Sādhanā Vol. 37, Part 2, April 2012, pp. 223-240. (C) Indian Academy of Sciences

\title{
Multi-objective parametric optimization of powder mixed electro-discharge machining using response surface methodology and non-dominated sorting genetic algorithm
}

\author{
SOUMYAKANT PADHEE ${ }^{1}$, NIHARRANJAN NAYAK ${ }^{2}$, \\ $\mathrm{S} \mathrm{K} \mathrm{PANDA}^{2}$, P R DHAL ${ }^{2}$ and S S MAHAPATRA ${ }^{2, *}$ \\ ${ }^{1}$ Department of Manufacturing Science and Technology, Veer Surendra \\ Sai University of Technology, Sambalpur 768 018, India \\ ${ }^{2}$ Department of Mechanical Engineering, National Institute of Technology, \\ Rourkela 769 008, India \\ e-mail: soumyakantpadhee2011@gmail.com; nihar204@gmail.com; \\ samirpanda.nitrkl@gmail.com; prdhal@gmail.com; mahapatrass2003@yahoo.com
}

MS received 31 March 2010; revised 23 October 2011; accepted 13 December 2011

\begin{abstract}
Powder mixed electro-discharge machining (EDM) is being widely used in modern metal working industry for producing complex cavities in dies and moulds which are otherwise difficult to create by conventional machining route. It has been experimentally demonstrated that the presence of suspended particle in dielectric fluid significantly increases the surface finish and machining efficiency of EDM process. Concentration of powder (silicon) in the dielectric fluid, pulse on time, duty cycle, and peak current are taken as independent variables on which the machining performance was analysed in terms of material removal rate (MRR) and surface roughness (SR). Experiments have been conducted on an EZNC fuzzy logic Die Sinking EDM machine manufactured by Electronica Machine Tools Ltd. India. A copper electrode having diameter of $25 \mathrm{~mm}$ is used to cut EN 31 steel for one hour in each trial. Response surface methodology (RSM) is adopted to study the effect of independent variables on responses and develop predictive models. It is desired to obtain optimal parameter setting that aims at decreasing surface roughness along with larger material removal rate. Since the responses are conflicting in nature, it is difficult to obtain a single combination of cutting parameters satisfying both the objectives in any one solution. Therefore, it is essential to explore the optimization landscape to generate the set of dominant solutions. Non-sorted genetic algorithm (NSGA) has been adopted to optimize the responses such that a set of mutually dominant solutions are found over a wide range of machining parameters.
\end{abstract}

Keywords. Powder mixed EDM; surface roughness; material removal rate; non-sorted genetic algorithm; response surface methodology.

*For correspondence 


\section{Introduction}

Electrical discharge machining (EDM) is an extensively used non-conventional material removal process to machine electrically conductive and hard materials for manufacturing of mould, die, automotive, aerospace and surgical components (Benedict 1987). In this process, material is removed by controlled erosion through a series of electric sparks between the tool (electrode) and the work piece. The thermal energy of the sparks leads to intense heat conditions on the work piece causing melting and vaporizing of work piece material. Sometimes its low machining efficiency and poor surface finish restricts application. To diffuse this problem, EDM in the presence of powder suspended in the dielectric fluid is used and known as powder mixed EDM (PMEDM) (Mohri et al 1991; Jeswani 1981; Tzeng \& Chen 2003; Furutani et al 2001). The electrically conductive powder reduces the insulating strength of the dielectric fluid and increases the spark gap between the tool and work piece (Wong et al 1998; Ming \& He 1995; Chow et al 2000; Schumacher 1990). As a result, the process becomes more stable and thereby improves material removal rate (MRR) and surface finish (SF). The presence of powder increases the gap distance as compared to traditional EDM by at least a factor of two (Wong et al 1998). The enlarged and widened discharge channel lowers the break down strength of the dielectric fluid and reduces the electrical density on the machining spot. By reducing the spark energy and dispersing the discharges more uniformly throughout the surface, shallow craters are generated (Singh et al 2005; Ming \& He 1995; Chow et al 2000; Pecas \& Henriques 2003). However, it is difficult to establish the relationship between PMEDM process parameters and responses because the process is too complex in nature. Therefore, response surface methodology (RSM) can be adopted for modelling and analysis using experimental data and studying the influence of various process parameters on responses (Montgomery 1997). Based on the models of the responses, non-sorted genetic algorithm (NSGA) can be used to search for the non-dominant optimal solutions. In the absence of any further information, one of these pareto-optimal solutions cannot be said to be better than the other. Suitability of one solution depends on a number of factors including user's choice and problem environment. Therefore, a set of dominant solution is determined and Pareto front is predicted.

\section{Literature review}

Material removal rate and surface roughness (SR), being two important responses in die-sinking PMEDM, several researchers carried out various investigations for improving the process performance. Proper selection of machining parameters for the best process performance is still a challenging job. To solve this type of multi-optimization problem in EDM, Lin et al (2001a, b), Lin \& Lin (2005) used grey relation analysis based on an orthogonal array and fuzzy based Taguchi method. Wang et al (2003) used genetic algorithm (GA) with artificial neural network (ANN) to find out optimal process parameters for improving performances. A similar approach has been considered by Su et al (2004) from the rough cutting to the finish cutting stage. In most of the studies, multiple objectives are transformed into a single objective and attempts to find optimal parameters. However, Kuriakose \& Shunmugam (2005) have used non-dominated sorting genetic algorithm (NSGA) to optimize machining parameters in WEDM considering surface roughness and cutting speed as the output parameters. Multiple linear regression models have been developed to represent the relation between inputs and outputs. In PMEDM process, it is possible to achieve near mirror-finish using conductive powders such as graphite and aluminum 
and semi-conductive silicon powders (Wong et al 1995, 1998). It has been shown that besides the appropriate settings of electrode polarity and pulse parameters, there is a great influence of work material and powder properties on the responses like MRR, tool wear rate (TWR) and SR. The effect of impurities (copper, aluminum, iron and carbon) in dielectric fluid of EDM was reported in the literature. It was shown that the machining rate increased with increasing the concentration of the powder due to decrease in the time lag. Jeswani (1981) has reported through experimental investigation that addition of $4 \mathrm{~g} / \mathrm{l}$ graphite powder into kerosene oil improves MRR by $60 \%$ and reduces wear ratio by $15 \%$. Mohri et al (1991) studied the effects of addition of silicon powder on machining rate and SR. They have demonstrated that fine and corrosion resistant surfaces having roughness of the order of $2 \mu \mathrm{m}$ can be produced. However, this performance could only be achieved at controlled machining conditions (even distribution of additives into dielectric, short discharge time, etc.). It was further reported that under specific working conditions, aluminum and graphite powders exhibit more improvement in surface finish than caused by silicon powder. The glossy and smooth surface finish can be achieved by mixing the different additives (silicon, graphite, molybdenum, aluminum, and silicon carbide) into the dielectric fluid of EDM (Wong et al 1998).

Metal removal process in EDM is characterized by nonlinear, stochastic and time varying characteristics. In EDM, a quantitative relationship between the operating parameters and controllable input variables is often required. Many regression techniques have been used for modelling the EDM process (Abbas et al 2007). Neural networks and fuzzy systems form an alternative approach to generalize the experimental results and develop the system model accurately. Unlike milling and drilling operations, operating speeds in EDM are very low. Large electric current discharge can enhance speeds but reduces the dimensional quality of machined surface. Similarly, the material removal rate is also affected by other process parameters. These parameters are selected from standard tables or by experience to improve the output performance of the process. Even in the computer controlled environments involving online process control, this selection is not an easy task. Presently many optimization techniques are being used in EDM practice to obtain the best process parameters. Kansal et al (2005) adopted the response surface optimization scheme to select the parameters in powder mixed EDM process. Keskin et al (2006) used design of experiments (DOE) for the determination of the best machining parameters in EDM. Tzeng \& Chen (2007) employed a Taguchi fuzzy-based approach for solving the multi-objective optimization problems in high-speed EDM process. Mandal et al (2007) have shown the modelling procedure of EDM using neural networks and solution methodology using GA. More recently Yuan et al (2008) illustrated the optimization process of high-speed wire EDM process using regression methods. Nixon \& Ravindra (2011) have investigated influence of parameters and optimization of wire EDM of hot die steel using Taguchi method. In all the above cases multi-objective formulations are solved for online selection of design variables.

Researchers are now focusing on employment of artificial intelligence (AI) techniques viz. ANN, GA, fuzzy logic, etc. for the process modelling and optimization of manufacturing processes which are expected to overcome some of the limitations of conventional process modelling techniques. Fenggou \& Dayong (2004) have proposed another GA-based ANN modelling approach for the prediction of the processing depth. The number of nodes in the hidden layer was optimized by using GA. Panda \& Bhoi (2005) have used back propagation neural network (BPNN) with Levenberg-Marquardt (LM) algorithm for the prediction of MRR. Later, Sen \& Shan (2007), Gao et al (2008), Rao et al (2008) followed the similar methodology for the modelling and optimization of EDM process for different work-tool material pairs. Recently, Yang et al (2009) used simulated annealing (SA) technique with ANN for optimization of MRR and 
surface roughness. Somashekhar et al (2010) have studied optimization of material removal rate in micro-EDM using artificial neural network and genetic algorithms. Kanagarajan et al (2008) have reported an optimization framework for electrical discharge machining characteristics of WC/Co composites using non-dominated sorting genetic algorithm (NSGA-II). Zhang et al (2010) have used a hybrid model using supporting vector machine and multi-objective genetic algorithm for processing parameters optimization in micro-EDM. Joshi \& Pande (2011) have proposed an intelligent process modelling of die-sinking electric discharge machining using finite element modelling (FEM) for data generation and optimization of parameters by integrating ANN with NSGA II.

\section{Multi-objective optimization}

Genetic algorithm (GA) is a subclass of population based stochastic search procedure which is closely modelled on the natural process of evolution with emphasis on breeding and the survival of the fittest. Instead of starting with a single point, the algorithm starts with a set of initial solutions. Also, instead of a deterministic result at each iteration, GA operators produce probabilistic results leading to stochasticity. Proper search direction can be provided to the GA by simulating the natural process of evolution. In the process of evolution, the organisms which are able to adapt better to the environment have a higher chance of survival. This leads to a higher chance of breeding for such organisms and an increased probability of their traits being carried over to the next generation through their offspring. Thus, a trait which leads to a better organism has higher chances of making it to the next generation. Moreover, due to mating of two different organisms with better fitness leads to intermixing of favourable traits which hopefully would lead to better offspring. In case the new members with poor adaptability, they would be lost in the next generation. At the same time, it is important to maintain diversity in the population so that potentially important regions of the search space are not eliminated during the initial stages.

To keep a track of which traits are favourable and which are not, traits are coded in the form of genetic material which is stored in a chromosome. Due to selection of better traits and intermixing, eventually the entire population has the same chromosome set which is also the best possible trait combination.

- To incorporate the idea of natural evolution, GA must have the following essential features.

- Encoding of solution: To keep track of favourable solutions.

- Assigning fitness to a solution: To determine the chances of survival of the solution.

- Selection operator: To select the fit solutions for mating.

- Crossover or recombination operator: For mixing of traits through mating of two different solutions.

- Mutation operator: Random variations in encoded solutions to obtain new solutions.

- Survivor operator: To determine the members which die off and those which go to the next generation.

These operators are responsible for providing the search direction to a GA. Selection operator selects good solutions and crossover operator recombines good genetic material from two good solutions to (hopefully) form a better solution. Mutation operator alters a string locally to (hopefully) create a better string. If bad strings are created they are eliminated by the reproduction operator in the next generation and if good strings are created, they are emphasized. 
In a single objective optimization, there exists only one solution. But in the case of multiple objectives, there is a set of mutually dominant solution, which is exclusive and unique with respect to all objectives. Classical methods for solving multi-objective problem suffer from drawback of trading off among objectives when a weighted function is used. These methods transform the multi-objective problem into single objective by assigning some weights based on their relative importance (Yu et al 2004). However, most of the multi-objective problems, in principle, give rise to a set of optimal solutions instead of a single optimal solution. The set of solution is known as pareto-optimal solution.

Real-world problems require simultaneous optimization of several incommensurable and often conflicting objectives. Often, there is no single optimal solution; rather there is a set of alternative solutions. These solutions are optimal in the wider sense that no other solutions in the search space are superior to another when all objectives are considered. They are known as pareto-optimal solutions. The image of the efficient set in the objective space is called nondominated set. For example, consider a minimization problem and two decision vectors $\mathrm{a}, \mathrm{b} \varepsilon \mathrm{X}$, the concept of pareto optimality can be defined as follows: a is said to dominate b if:

$$
\begin{gathered}
\mathrm{i}=\{1,2, \ldots, \mathrm{n}\}: \mathrm{fi}(\mathrm{a}) \leq \mathrm{fi}(\mathrm{b}) \text { and } \\
\mathrm{j}=\{1,2, \ldots, \mathrm{n}\}: \mathrm{fj}(\mathrm{a})<\mathrm{fj}(\mathrm{b}) .
\end{gathered}
$$

Conditions which a solution should satisfy to become dominant are; (i) any two solutions of $\mathrm{X}$ must be non-dominated with respect to each other, (ii) any solution not belonging to $\mathrm{X}$ is dominated by at least one member of X. All the objective function vectors, which are not dominated by any other objective function vector of a set of Pareto-optimal solutions are called non-dominated set with respect to that set of Pareto-optimal solutions. There are two goals in a multi-objective optimization: (i) convergence to the Pareto-optimal set; and (ii) maintenance of diversity and distribution in solutions.

Non-dominated Sorting Genetic Algorithm II (NSGA II) is a multi-objective evolutionary algorithm based on non-dominated sorting (Deb et al 2002). The algorithm uses elitist non-dominated sorting along with crowding distance sorting to obtain the non-dominated set. The algorithm is capable of handling constrained multi-objective optimization problems with binary coding and real parameters. The appropriate objective function in terms of the variables is coded in the algorithm. The algorithm produces the non-dominated set out of the entire population after a specific number of generations. Members of Pareto-front belong to the nondominated set which is obtained on convergence of the algorithm. Selection is done with the help of crowded-comparison operator based on ranking (according to non-domination level) and crowding distance.

Randomly an initially parent population (solution) $P$ of size $N$ is generated. In order to identify the non-domination level, each solution is compared with every other solution and checked whether the solution under consideration satisfies the rules given below

$$
\begin{gathered}
\text { Obj.1 }[i]>\operatorname{Obj} .1[j] \text { and Obj.2 }[i] \geq \operatorname{Obj} .2[j], \\
\text { or Obj.1 }[i] \geq \operatorname{Obj} .1[j] \text { and Obj.2 }[i]>\operatorname{Obj} .2[j],
\end{gathered}
$$

where $i$ and $j$ are chromosome numbers. 
Now if the rules are satisfied, then the selected solution is marked as dominated. Otherwise, the selected solution is marked as non-dominated. In the first sorting, all the non-dominated solution $(N 1)$ is assigned to rank 1 . From the remaining $N-N 1$ dominated solution from the first sorting, again solution are sorted to and the non-dominated solutions in second sorting are assigned to rank 2. This process continues until all the solutions are ranked. Each solution is assigned fitness equal to its non-domination level (rank 1 is the best level, rank 2 is the next-best level, and so on). Solutions belong to a particular rank or non-domination level, none of the solution is better with respect to other solutions present in that non-domination level. After identifying the rank of each solution, crowding distance of each solution belongs to a particular non-domination set or level is calculated. The crowding distance is the average distance of two points on either side of this selected solution point along each of the objectives function. For calculation of crowded distance, all the populations of particular non-dominated set are sorted in ascending order of magnitude according to each objective function value. Then, the boundary solution of each objective function, i.e., solution with largest and smallest values is assigned an infinity value. Rest of the intermediate solutions are assigned to a distance value equal to the absolute normalized difference in the function value at two adjacent solutions. For solving optimization problem using GA, it needs fitness value. The fitness values are nothing but the objective function values. Therefore, there is a need of function or equation, which relates the decision variable with the objective.

\section{Methods and materials}

\subsection{Powder mixed electro-discharge machining (PMEDM)}

Machining mechanism in PMEDM is slightly different from conventional EDM process. In this process, a suitable material in the powder form is mixed into the dielectric fluid in the machining tank. Machining is performed in this tank and workpiece is placed in it, holding it with the help of a workpiece fixture assembly. The machining tank is filled up with dielectric fluid (kerosene oil) and to avoid particle settling, a stirring system is incorporated. A small dielectric circulation pump is installed for proper circulation of the powder mixed dielectric fluid into the discharge gap. The distance between powder mixed dielectric suction point and nozzle outlet is kept as short as possible $(250 \mathrm{~mm})$ in order to ensure the complete suspension of powder in the discharge gap. Two permanent magnets are placed at the bottom of machining tank to separate the debris from the dielectric fluid. Electric sparks are generated between two electrodes when the electrodes are held at a small distance from each other in a dielectric medium and a high potential difference is applied across them in conventional EDM. But the presence of suspended powder decreases the break down strength of the dielectric fluid and reduces the electrical density on the machining spot. Localized regions of high temperatures are formed due to the sparks occurring between the two electrode surfaces. Workpiece material in this localized zone melts and vaporizes. Most of the molten and vaporized material is carried away from the inter-electrode gap by the dielectric flow in the form of debris particles. To prevent excessive heating, electric power is supplied in the form of short pulses. Spark occurs wherever the gap between the tool and the workpiece surface reaches a point to which the powder had lowered the electric density. The spark gap used to produce spark in PMEDM is twice as much as the gap needed to produce spark in conventional EDM. This way several sparks occur at various locations over the entire surface of the workpiece corresponding to the workpiece-tool gap. A schematic diagram of PMEDM is shown in figure 1. 


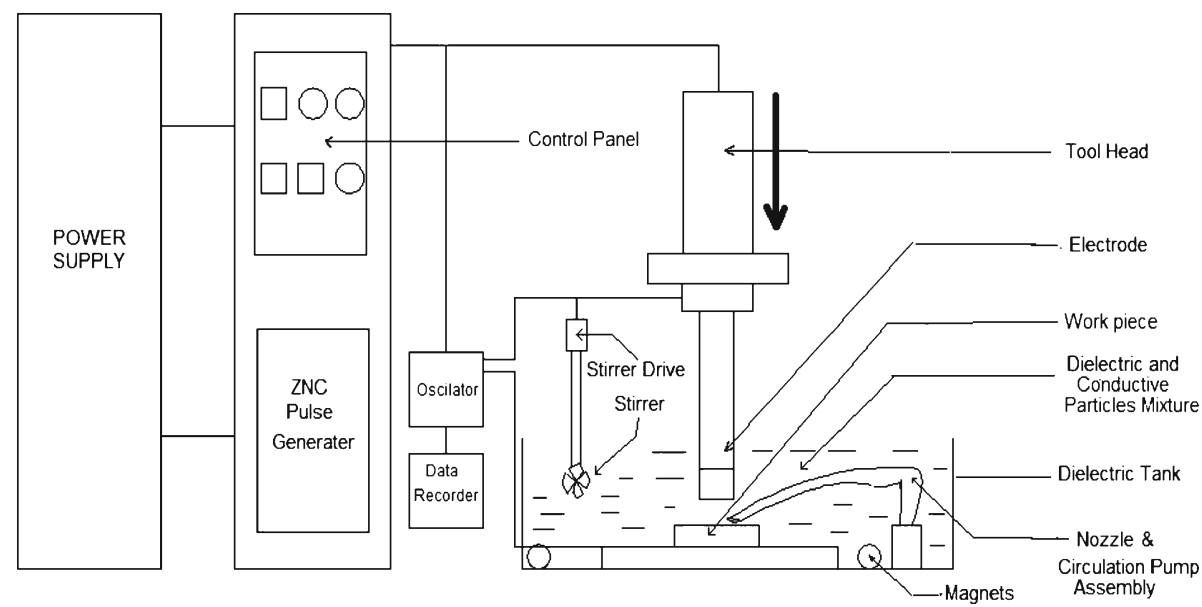

Figure 1. Schematic diagram of experimental set-up.

\subsection{Selection of input and output parameters}

The literature study suggests that there are many electrical (peak current, polarity, pulse duration, power supply voltage), non-electrical (flushing pressure, type of dielectric, temperature), powder (type of powder, powder concentration, shape and size) and electrode (material, size) parameters greatly affect the machining performances in PMEDM, especially to MRR and SF (Pecas \& Henriques 2008). The input parameters considered in this study are defined as follows:

4.2a Pulse on time (A): The duration of time ( $\mu \mathrm{s})$, the current is allowed to flow per cycle. Material removal is directly proportional to the amount of energy applied during on-time. Amount of energy is really controlled by the peak current and the length of the on-time.

$4.2 \mathrm{~b}$ Duty factor $(B)$ : It is a percentage of the on-time relative to the total cycle time. This parameter is calculated by dividing the on-time by the total cycle time (on-time plus off-time).

4.2c Peak current $(C)$ : The Peak current (Ip) is a measure of the power supplied to the discharge gap. A higher current leads to a higher pulse energy and formation of deeper discharge craters. This increases the material removal rate (MRR) and the surface roughness ( $\mathrm{Ra})$ value. It is expressed in amperes.

$4.2 \mathrm{~d}$ Concentration of conductive powder $(D)$ : The concentration of conductive particles present in the dielectric fluid increases the susceptibility of formation of conductive bridges and decreases the insulation of dielectric fluid so that spark is generated even from a larger spark gap. It is expressed in terms of gm per liters. Constant stirring is required to facilitate uniform distribution of particles in the dielectric.

The output parameters considered are defined as follows.

4.2e Metal removal rate (MRR): It is denoted by volume of material removed per minute. MRR is an important indicator of efficiency and cost effectiveness of the EDM process. However, increasing MRR is not always desirable in all applications because it may adversely affect the surface integrity of the work piece. A rough surface finish is the usual, where there is fast removal rates. MRR is calculated by the weight loss method and expressed as $\mathrm{mm}^{3} / \mathrm{min}$. 
Weight loss is estimated using Mettler Toledo precision balance having capacity of $5 \mathrm{~kg}$ and precision of $0.01 \mathrm{~g}$.

4.2f Surface roughness ( $R a$ ) of work piece: The surface produced by EDM process consists of a large number of craters that are formed from the discharge energy. The quality of surface mainly depends on the energy per spark. The undulations of the surface are usually measured in a sampling length using a sensor. The arithmetic mean roughness of the evaluated roughness profile $(\mathrm{Ra}$ in $\mu \mathrm{m})$ is noted using a Surfcoder SE 1200 surface testing analyzer supplied by Metrology International Ltd., UK.

\subsection{Experimental data collection}

Experiments are conducted on EZNC fuzzy logic Die Sinking EDM machine manufactured by Electronica Machine Tools Ltd. India. Silicon powder is suspended into the commercially available kerosene oil. The average particle size of the powder is in the range of order 20-30 $\mu \mathrm{m}$. Each trial run as per the array given in table 2 by setting the controlled parameters at desired levels is performed for a duration of $60 \mathrm{~min}$. The experiment has been performed with positive polarity as recommended in Zhao et al (2002). In this study, EN 31 (comparable to AISI 52100) tool steel is selected as the work material. The chemical composition of the workpiece material is given as $\mathrm{C}=0.9-1.2 \%, \mathrm{Si}=0.1-0.3 \%, \mathrm{Mn}=0.3-0.7 \%, \mathrm{Cr}=1-1.6 \%$, $\mathrm{S}$ and $\mathrm{P}$ each $0.025 \%$ (max.) and balance is ferrous. The hardness (HRC), Young's modulus and density of the work piece are 58-63 HRC, $208 \mathrm{GPa}$ and $7.85 \mathrm{~g} / \mathrm{cm}^{3}$, respectively. Copper electrode with diameter $25 \mathrm{~mm}$ has been used to machine workpiece. A photograph of the machine is shown in figure 2. The generated depression of diameter $25 \mathrm{~mm}$ in the work piece is evaluated for material removal rate and surface finish. Surface roughness is measured with the help of Surfcoder SE 1200 surface testing analyzer. The surface analyzer has drive 0-25 $\mathrm{mm}$ traverse

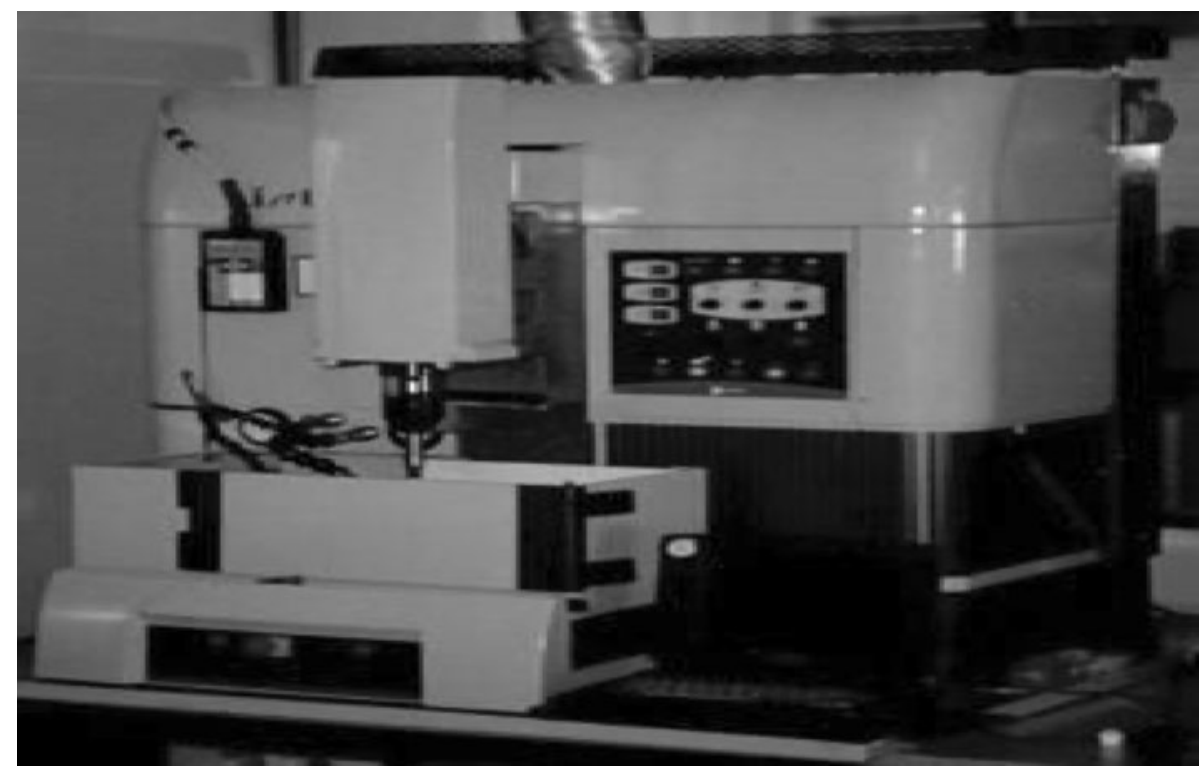

Figure 2. EZNC fuzzy logic die sinking EDM machine manufactured by Electronica Machine Tools Ltd. India. 
with inbuilt straight datum, range to resolution is $520 \mu \mathrm{m}$ to $0.008 \mu \mathrm{m}$, and two driver speeds $0.2 \mathrm{~mm} / \mathrm{sec}$ and $0.5 \mathrm{~mm} / \mathrm{sec}$. For calculating material removal rate, first weight loss is estimated using the precision balance by noting down weight of work piece before and after machining. The weight loss is multiplied by density and divided by time of machining to obtain the material removal rate.

In order to assess the impact of four process parameters on two responses, a large number of experiments need to be conducted using conventional experimental data collection method. However, by using response surface methodology the number of experimental runs can be reduced to a large extent and both effect of factors and their possible interactions can be studied. By doing so, predictive equations can be developed and statistically validated. In RSM, the quantitative form of the relationship between desired response and independent input variables can be represented by the following:

$$
y=f\left(x_{1}, x_{2}, \ldots, x_{k}\right)+\varepsilon,
$$

where the response variable (output) y depends on the controllable (input) variables $x_{1}, x_{2}, \ldots$, $x_{k}$ and $f$ are the response function (or response surface). The true form of the response variable $\mathrm{y}$ is seldom known for a process. In RSM, the true relationship between y and the independent variables is generally approximated by the lower-order polynomial models such as:

$$
\begin{gathered}
y=\beta_{0}+\beta_{1} x_{1}+\ldots . .+\beta_{k} x_{k}+\varepsilon, \\
y=\beta_{0}+\sum_{i=1}^{k} \beta_{i} x_{i}+\sum_{i=1}^{k} \beta_{i i} x_{i}^{2}+\sum_{i<j}^{k} \beta_{i j} x_{i} x_{j}+\varepsilon,
\end{gathered}
$$

where $\varepsilon$ represents the statistical error term. Here, the $\beta$ 's are the unknown parameters estimated by first collecting data on the system and then performing statistical model building by using regression analysis. Here, a face centred central composite design (FCCCD) is used to conduct the experiments. FCCD designs comprise a set of two-level factorial points, axial points and centre runs. In fact, FCCD can be created from central composite design (CCD) by setting axial distance $(\alpha=1)$. This is desirable when each factor is considered at three levels and axial runs not to be any more extreme values than the factorial portion is ensured. The factorial points contribute to the estimation of linear terms and two-factor interactions. Factorial points are the only points which contribute to estimation of the interaction terms. The axial points contribute to the estimation of quadratic terms. The centre runs provide an internal estimate of pure error and contribute towards the estimation of quadratic terms. Each factor (A, B, C and D) is considered at three levels. The range of each factor is shown in table 1.

Table 1. Factors and their levels.

\begin{tabular}{llccc}
\hline & & \multicolumn{3}{c}{ Levels } \\
\cline { 3 - 5 } Factor symbol & Parameter & Low $(-1)$ & Medium $(0)$ & High $(+1)$ \\
\hline A & Pulse on time $(\mu \mathrm{s})$ & 50 & 100 & 150 \\
$\mathrm{~B}$ & Duty factor & 0.7 & 0.8 & 0.9 \\
$\mathrm{C}$ & Peak current (amp.) & 3 & 7.5 & 12 \\
$\mathrm{D}$ & Concentration $(\mathrm{g} / \mathrm{l})$ & 0 & 1 & 2 \\
\hline
\end{tabular}


The factors are coded in the range of -1 to +1 using following relation.

$$
\begin{gathered}
\xi_{i j}=\left(\frac{X_{i j}-\left(\frac{X_{i_{\max }}+X_{i_{\min }}}{2}\right)}{X_{i_{\max }}+X_{i_{\min }}}\right) * 2 \\
1 \leq i \leq 4,1 \leq j \leq 2,
\end{gathered}
$$

where $\xi_{i j}$ and $X_{i j}$ are coded and actual value of $j$ th level of $i$ th factor, respectively. $X_{i_{\max }}$ and $X_{i_{\min }}$ maximum and minimum range of factor $X_{i}$.

The PMEDM process is studied with a standard FCCCD. In this investigation, total thirty experiments were conducted maintaining factors at designated levels as shown in table 2 . The experimental runs sixteen factorial points (a full factorial design with all combinations of the

\begin{tabular}{|c|c|c|c|c|c|c|}
\hline Expt. No. & $\begin{array}{c}\text { Pulse on time, } \\
\mathrm{A}(\mu \mathrm{s})\end{array}$ & $\begin{array}{l}\text { Duty factor, } \\
\text { B }\end{array}$ & $\begin{array}{c}\text { Peak current, } \\
\text { C (Amp.) }\end{array}$ & $\begin{array}{c}\text { Concentration } \\
\text { of abrasive, } \\
\text { D (g/l) }\end{array}$ & $\begin{array}{c}\text { MRR } \\
\left(\mathrm{mm}^{3} / \mathrm{min}\right)\end{array}$ & $\begin{array}{c}\mathrm{SR}, \mathrm{R}_{\mathrm{a}} \\
(\mu \mathrm{m})\end{array}$ \\
\hline 1 & 50 & 0.7 & 3 & 0 & 2.000 & 2.345 \\
\hline 2 & 150 & 0.7 & 3 & 0 & 2.300 & 2.030 \\
\hline 3 & 50 & 0.9 & 3 & 0 & 2.200 & 2.270 \\
\hline 4 & 150 & 0.9 & 3 & 0 & 2.300 & 2.230 \\
\hline 5 & 50 & 0.7 & 12 & 0 & 22.800 & 6.80 \\
\hline 6 & 150 & 0.7 & 12 & 0 & 23.900 & 7.710 \\
\hline 7 & 50 & 0.9 & 12 & 0 & 22.600 & 7.710 \\
\hline 8 & 150 & 0.9 & 12 & 0 & 24.600 & 6.730 \\
\hline 9 & 50 & 0.7 & 3 & 2 & 3.100 & 2.210 \\
\hline 10 & 150 & 0.7 & 3 & 2 & 3.500 & 1.360 \\
\hline 11 & 50 & 0.9 & 3 & 2 & 3.200 & 4.050 \\
\hline 12 & 150 & 0.9 & 3 & 2 & 3.300 & 1.220 \\
\hline 13 & 50 & 0.7 & 12 & 2 & 26.100 & 5.220 \\
\hline 14 & 150 & 0.7 & 12 & 2 & 28.800 & 5.080 \\
\hline 15 & 50 & 0.9 & 12 & 2 & 26.200 & 5.220 \\
\hline 16 & 150 & 0.9 & 12 & 2 & 28.700 & 5.200 \\
\hline 17 & 50 & 0.8 & 7.5 & 1 & 4.700 & 5.610 \\
\hline 18 & 150 & 0.8 & 7.5 & 1 & 7.200 & 6.880 \\
\hline 19 & 100 & 0.7 & 7.5 & 1 & 6.300 & 5.970 \\
\hline 20 & 100 & 0.9 & 7.5 & 1 & 7.400 & 6.370 \\
\hline 21 & 100 & 0.8 & 3 & 1 & 2.300 & 1.870 \\
\hline 22 & 100 & 0.8 & 12 & 1 & 25.100 & 5.970 \\
\hline 23 & 100 & 0.8 & 7.5 & 0 & 6.200 & 6.780 \\
\hline 24 & 100 & 0.8 & 7.5 & 2 & 7.300 & 4.820 \\
\hline 25 & 100 & 0.8 & 7.5 & 1 & 6.555 & 6.395 \\
\hline 26 & 100 & 0.8 & 7.5 & 1 & 6.730 & 6.800 \\
\hline 27 & 100 & 0.8 & 7.5 & 1 & 7.395 & 6.800 \\
\hline 28 & 100 & 0.8 & 7.5 & 1 & 6.405 & 6.195 \\
\hline 29 & 100 & 0.8 & 7.5 & 1 & 7.540 & 6.150 \\
\hline 30 & 100 & 0.8 & 7.5 & 1 & 6.715 & 5.980 \\
\hline
\end{tabular}

Table 2. Design of experimental matrix and results for the PMEDM performance characteristics. 
factors at the two levels), eight axial points at the face corresponding to $\alpha$ value of one, and six central points. The responses such as MRR and SR are noted down for all experimental runs as shown in table 2 .

\section{Results and discussions}

Design Expert R 8.0 software is used for analysis of experimental data. A quadratic model is used to obtain the regression models for two responses separately. After eliminating insignificant terms, the final response equation for MRR is given as follows.

$$
\begin{aligned}
\text { MRR (Material Removal Rate) }= & 8.44840-2.41667 \times \mathrm{A}-3.28683 \times \mathrm{C}-0.025000 \times \mathrm{D} \\
+ & 2.05556 \times \mathrm{A} \times \mathrm{C}+0.16111 \times \mathrm{C} \times \mathrm{D}+0.36307 \times \mathrm{C}^{2} . \\
& (\text { in actual factors) } \\
\text { MRR (Material Removal Rate) }= & 6.70+0.65 \times \mathrm{A}+11.37 \times \mathrm{C}+1.18 \times \mathrm{D} \\
& +0.46 \times \mathrm{A} \times \mathrm{C}+0.73 \times \mathrm{C} \times \mathrm{D}+7.35 \times \mathrm{C}^{2} \\
& (\text { in coded terms) } .
\end{aligned}
$$

The analysis of variance (ANOVA) for MRR is presented in table 3. For significance check, $\mathrm{F}$ value given in table 3 is used. Probability of $\mathrm{F}$ value greater than calculated $\mathrm{F}$ value due to noise is indicated by $\mathrm{p}$ value. If $\mathrm{p}$ value is less than 0.05 , significance of corresponding term is established. For lack of fit, $\mathrm{p}$ value must be greater than 0.05 . An insignificant lack of fit is desirable because it indicates any term left out of model is not significant and developed model fits well. It is observed from last column that all the model parameters are significant. The lack of fit ( $\mathrm{p}$-value $=0.4356$ ) indicates that model is adequate. The coefficient of determination $\left(\mathrm{R}^{2}\right)$ and Adj. $\mathrm{R}^{2}$ are found to be 0.9978 and 0.9973 , respectively. As a further check, the normality test of residuals is carried out. It is evident from figure 3 that residuals are distributed as per normal distribution.

The analysis of variance (ANOVA) for SF is presented in table 4. The quadratic model for SR is given as follows. The coefficient of determination $\left(\mathrm{R}^{2}\right)$ and $\mathrm{Adj} . \mathrm{R}^{2}$ are found to be 0.92897

Table 3. ANOVA for MRR.

\begin{tabular}{lrcrrc}
\hline Source & $\begin{array}{c}\text { Sum } \\
\text { of squares }\end{array}$ & $\begin{array}{c}\text { Degrees } \\
\text { of freedom df }\end{array}$ & $\begin{array}{c}\text { Mean } \\
\text { square }\end{array}$ & F-Value & $\begin{array}{c}\text { p-value } \\
\text { prob }>\text { F }\end{array}$ \\
\hline Model & 2759.4600 & 6 & 459.9100 & 1777.9190 & $<0.0001$ \\
A & 7.6050 & 1 & 7.6050 & 29.3994 & $<0.0001$ \\
C & 2325.6200 & 1 & 2325.6200 & 8990.3790 & $<0.0001$ \\
D & 25.2050 & 1 & 25.2050 & 97.4375 & $<0.0001$ \\
A $\times$ C & 3.4225 & 1 & 3.4225 & 13.2307 & 0.0014 \\
C $\times$ D & 8.4100 & 1 & 8.4100 & 32.5114 & $<0.0001$ \\
C $^{2}$ & 389.1972 & 1 & 389.1972 & 1504.5580 & $<0.0001$ \\
Residual & 5.9496 & 23 & 0.2587 & & \\
Lack of fit & 4.8684 & 18 & 0.2705 & 1.2508 & 0.4356 \\
Pure error & 1.0812 & 5 & 0.2162 & & \\
Cor total & 2765.4090 & 29 & & & \\
\hline
\end{tabular}




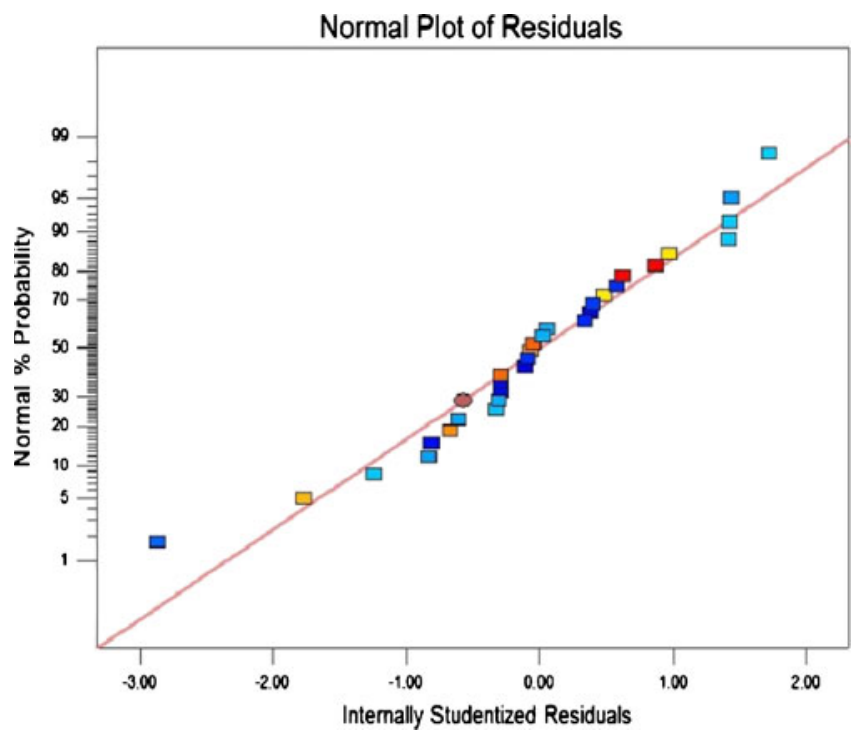

Figure 3. Normal plot of residuals for MRR.

and 0.9176 , respectively. It is evident from figure 4 that residuals are distributed as per normal distribution.

$$
\begin{aligned}
\mathrm{R}_{\mathrm{a}}(\text { Surface roughness })= & -3.08929+2.07746 \times \mathrm{C}+0.28559 \times \mathrm{D}-0.11382 \\
& \times \mathrm{C} \times \mathrm{D}-0.10123 \times \mathrm{C}^{2} \\
& (\text { in actual factors }) \\
\mathrm{R}_{\mathrm{a}}(\text { Surface roughness })= & 6.23+2.00 \times \mathrm{C}-0.57 \times \mathrm{D}-0.51 \times \mathrm{C} \times \mathrm{D}-2.05 \times \mathrm{C}^{2} \\
& (\text { in coded terms })
\end{aligned}
$$

The response plots for interactions of $\mathrm{A} \times \mathrm{C}$ and $\mathrm{C} \times \mathrm{D}$ are shown in figure 5 . It can be noted from figure 5a that increase in pulse on time (A) causes marginal increase in MRR whereas increase in peak current $(C)$ causes large increase in MRR. Similarly, increase in concentration of

Table 4. ANOVA for SR.

\begin{tabular}{lrcrrc}
\hline Source & $\begin{array}{c}\text { Sum } \\
\text { of squares }\end{array}$ & $\begin{array}{c}\text { Degrees } \\
\text { of freedom df }\end{array}$ & $\begin{array}{c}\text { Mean } \\
\text { square }\end{array}$ & F-Value & $\begin{array}{c}\text { p-value } \\
\text { prob }>\text { F }\end{array}$ \\
\hline Model & 112.4839 & 4 & 28.1209 & 81.7418 & $<0.0001$ \\
$\mathrm{C}$ & 72.2202 & 1 & 72.2202 & 209.9291 & $<0.0001$ \\
$\mathrm{D}$ & 5.8084 & 1 & 5.8084 & 16.8837 & 0.0004 \\
$\mathrm{C} \times \mathrm{D}$ & 4.1974 & 1 & 4.1974 & 12.2009 & 0.0018 \\
$\mathrm{C}^{2}$ & 30.2580 & 1 & 30.2580 & 87.9538 & $<0.0001$ \\
Residual & 8.6005 & 25 & 0.3440 & & \\
Lack of fit & 8.0006 & 20 & 0.4000 & 3.3343 & 0.0929 \\
Pure error & 0.5999 & 5 & 0.1199 & & \\
Cor total & 121.0845 & 29 & & & \\
\hline
\end{tabular}




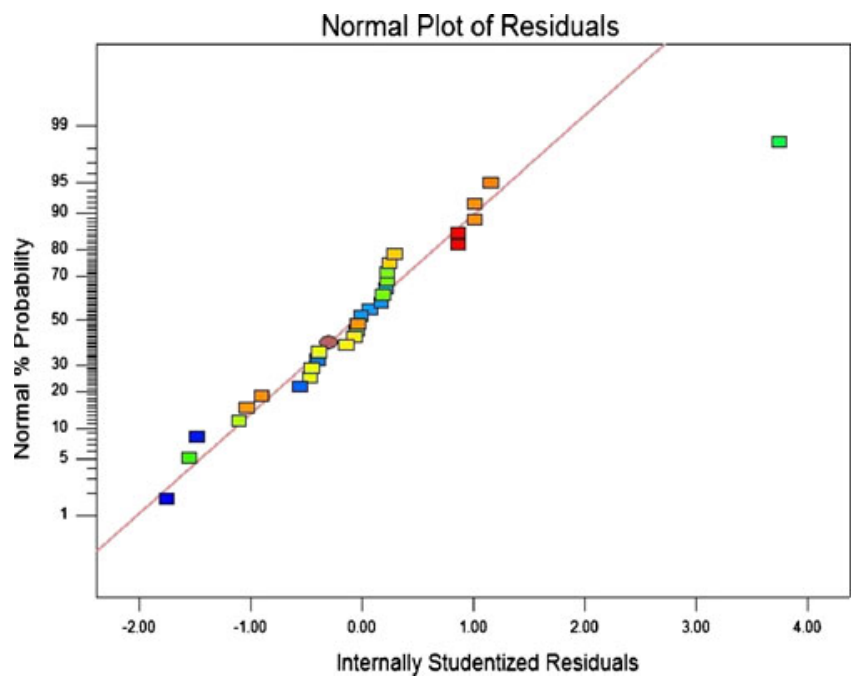

Figure 4. Normal plot of residuals for SR.

abrasives in dielectric fluid (D) causes increase in MRR (figure 5b). It is observed that change in duty factor does not have much significant effect on the MRR. Figure 6 indicates that increase in peak current (C) initially increases SR but further increase of peak current reduces SR. It can be clearly observed that increase in concentration of abrasives in dielectric fluid (D) monotonously decreases SR. The change in pulse on time and duty factor does show appreciable change in surface roughness value. Surface roughness increases marginally with increase in pulse on time. Again, change in duty factor does not have much significant effect on the SR.

In the present study, the objectives are maximization of MRR and minimization of SR, which are functions of decision variables viz., pulse on time (A), duty factor (B), peak current (C), and concentration of the added silicon powder (D). But there is no such mathematical equation, which relates to these objectives with the decision variable. Thus empirical relation between
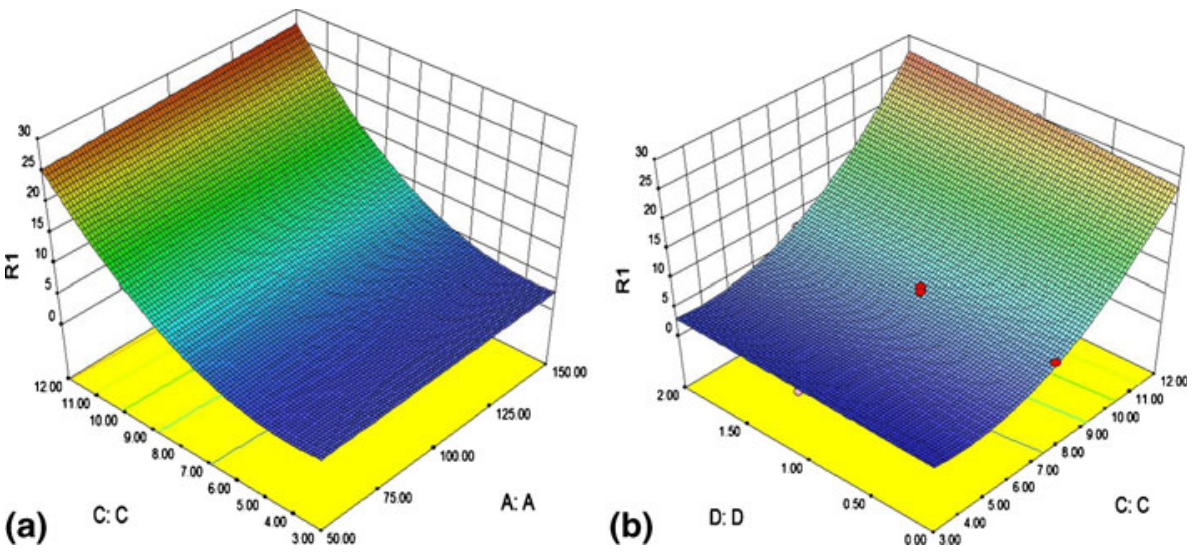

Figure 5. (a) Response plot of $\mathrm{A} \times \mathrm{C}$ for MRR. (b) Response plot of $\mathrm{C} \times \mathrm{D}$ for MRR. 


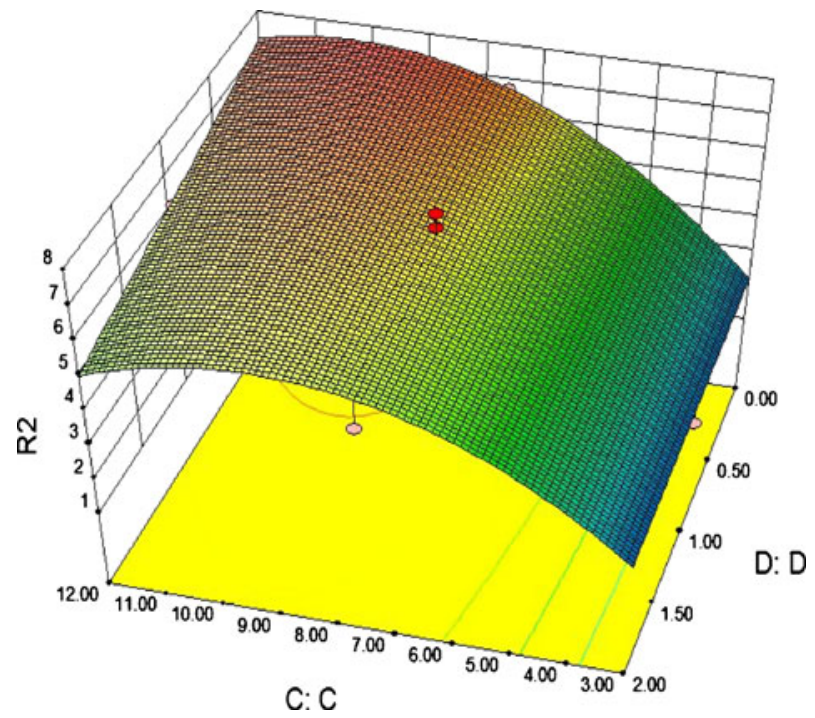

Figure 6. Response plot of $\mathrm{C} \times \mathrm{D}$ for $\mathrm{SR}$.

input parameters and output parameters obtained from the RSM analysis is used as functional equations. Note that objectives are conflicting in nature. In order to convert the first objective (MRR) as minimization one, it is suitably modified. The objective functions are given below.

$$
\text { Objective } 1=-(\mathrm{MRR})
$$

Objective 2 = Surface roughness.

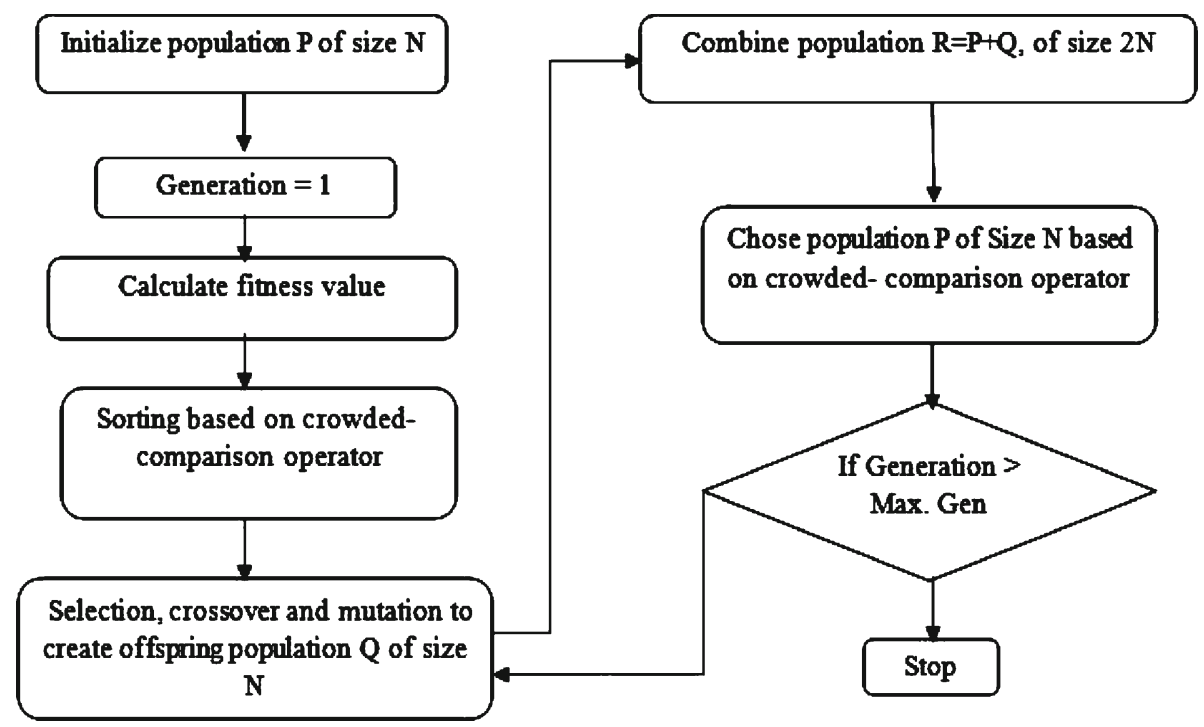

Figure 7. Flow chart of NSGA-II algorithm. 
There are four decision variables. The range and the step length of decision variables are different, and hence different lengths of bits have been used for each decision variable. Here, the range of pulse on time (A) is between 50 and $150 \mu$ s, so bit length is taken as 17 . For the other three variables, the ranges are much lower than $\mathrm{A}$, therefore bit lengths of 5, 13, and 13 have been taken to represent each of other three decision (B, C, and D) variables, respectively. Therefore, the total bit length of each chromosome is 48. Initially, the chromosomes are created randomly. An initial size of 100 populations is chosen. Simple crossover and bit-wise mutation have been used with a crossover probability, $\mathrm{Pc}=0.6$ and mutation probability, $\mathrm{Pm}=0.017$. Objective values are calculated from the RSM model as described earlier. Ranking and sorting of solutions have been done as it is mentioned in the NSGA-II algorithm. For achieving better convergence, a generation of 1000 is used in the study. 100 non-dominated solutions are obtained

Table 5. Selected solutions from pareto optimal solution set and corresponding variable settings.

\begin{tabular}{|c|c|c|c|c|c|}
\hline A & B & $\mathrm{C}$ & $\mathrm{D}$ & MRR & SR \\
\hline 150.0 & 0.829032 & 4.936028 & 0.250 & 12.66496 & 4.698705 \\
\hline 150.0 & 0.777419 & 5.779881 & 0.250 & 15.77635 & 5.536388 \\
\hline 150.0 & 0.816129 & 6.996215 & 0.249 & 21.17119 & 6.49016 \\
\hline 150.0 & 0.770968 & 6.865462 & 0.250 & 20.53979 & 6.40200 \\
\hline 150.0 & 0.841935 & 3.479062 & 0.250 & 8.510131 & 2.913048 \\
\hline 150.0 & 0.841935 & 4.82725 & 0.249 & 12.30164 & 4.580232 \\
\hline 150.0 & 0.841935 & 4.053718 & 0.250 & 9.964824 & 3.668671 \\
\hline 150.0 & 0.783871 & 8.270785 & 0.745 & 27.97672 & 7.168208 \\
\hline 150.0 & 0.841935 & 6.036992 & 0.250 & 16.82708 & 5.762964 \\
\hline 150.0 & 0.854839 & 5.217312 & 0.250 & 13.6448 & 4.993951 \\
\hline 150.0 & 0.841935 & 3.314247 & 0.250 & 8.13716 & 2.683992 \\
\hline 149.94 & 0.880645 & 6.79624 & 0.250 & 20.20978 & 6.353927 \\
\hline 150.0 & 0.816129 & 6.616042 & 0.250 & 19.36933 & 6.224232 \\
\hline 149.95 & 0.887097 & 7.920279 & 0.250 & 25.98077 & 7.014532 \\
\hline 150.0 & 0.816129 & 6.443536 & 0.249 & 18.58667 & 6.093914 \\
\hline 150.0 & 0.829032 & 5.952387 & 0.248 & 16.47609 & 5.689885 \\
\hline 150.0 & 0.841935 & 5.319497 & 0.250 & 14.01483 & 5.097242 \\
\hline 150.0 & 0.841935 & 5.882066 & 0.249 & 16.1883 & 5.62804 \\
\hline 150.0 & 0.867742 & 8.062019 & 0.250 & 26.78093 & 7.079672 \\
\hline 150.0 & 0.874194 & 4.255891 & 0.2497 & 10.53363 & 3.918614 \\
\hline 150.0 & 0.874194 & 4.228421 & 0.249 & 10.45456 & 3.885139 \\
\hline 150.0 & 0.880645 & 4.125137 & 0.250 & 10.1624 & 3.757911 \\
\hline 149.1 & 0.874194 & 3.280185 & 0.250 & 8.062501 & 2.635968 \\
\hline 150.0 & 0.790323 & 7.498352 & 0.2499 & 23.71129 & 6.796551 \\
\hline 150.0 & 0.841935 & 3.070321 & 0.2460 & 7.621312 & 2.334897 \\
\hline 150.0 & 0.887097 & 7.654377 & 0.250 & 24.53807 & 6.881358 \\
\hline 150.0 & 0.764516 & 5.068978 & 0.2497 & 13.12095 & 4.840251 \\
\hline 150.0 & 0.867742 & 7.147845 & 0.250 & 21.91877 & 6.588061 \\
\hline 150.0 & 0.816129 & 7.389574 & 0.250 & 23.14547 & 6.734509 \\
\hline 150.0 & 0.803226 & 7.741179 & 0.250 & 25.00563 & 6.926406 \\
\hline 150.0 & 0.816129 & 4.475644 & 0.250 & 11.18556 & 4.180904 \\
\hline 150.0 & 0.751613 & 3.626297 & 0.124 & 8.859986 & 3.11302 \\
\hline 149.60 & 0.816129 & 5.404102 & 0.250 & 14.29307 & 5.181162 \\
\hline 150.0 & 0.841935 & 6.303992 & 0.250 & 17.96913 & 5.984089 \\
\hline 150.0 & 0.829032 & 5.952387 & 0.248 & 16.47609 & 5.689885 \\
\hline
\end{tabular}




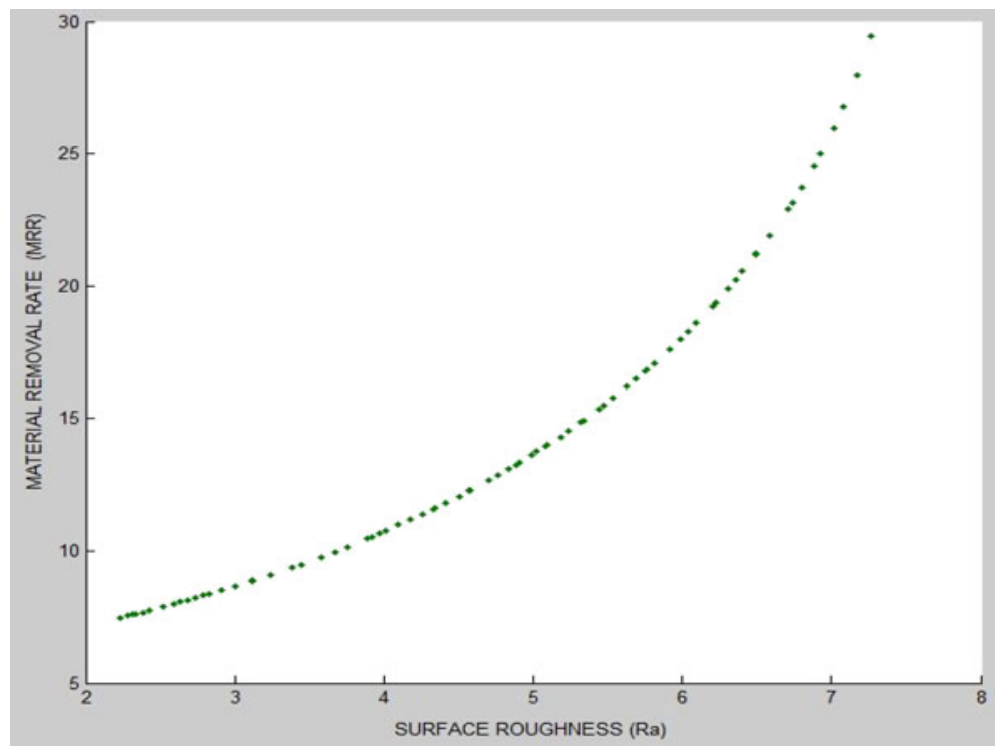

Figure 8. Graphical representation of Pareto-optimal front for objectives MRR and SR.

at the end of 1000 generation. The flow chart of NSGA II algorithm is shown in figure 7. The corresponding objective function values and the decision variables of selected non-dominated solution set are shown in table 5. Figure 8 shows the pareto-optimal solution front. This shows the formation of the pareto-optimal front leading to the final set of solutions. Since none of the solutions in the pareto-optimal front is absolutely better than any other, any one of them is an acceptable solution. The choice of one solution over the other depends on the requirement of the process engineer.

\section{Conclusions}

The experimental research work carried out in this study contributes to the generation of knowledge related to EDM technology using a powder-mixed dielectric. A large number of experiments have been conducted at different levels of factors viz., pulse on time, duty factor, peak current, and concentration of abrasive. The MRR and SR roughness have been measured for each setting. The use of powder mixed dielectric promotes the reduction of surface roughness and enhances material removal rate. Mathematical models for prediction of MRR and SR through the knowledge of four process variables have been developed using response surface methodology and statistically validated. The coefficient of determination $\left(\mathrm{R}^{2}\right)$ for MRR and SR models are found to be 0.99780 .92897 , respectively. It has been observed that linear terms A, C, and $\mathrm{D}$, interaction terms $\mathrm{A} \times \mathrm{C}$ and $\mathrm{C} \times \mathrm{D}$, and quadratic term $\mathrm{C}^{2}$ are statistically significant to be included in the model of MRR. Similarly, linear terms $C$ and $D$, interaction term $C \times D$, and quadratic term $\mathrm{C}^{2}$ are significant terms in the model of SR. In order to simultaneously optimize both MRR and SR, NSGA II is adopted to obtain the Pareto front. Since none of the solutions in the pareto-optimal front is said to be absolutely better than any other. Any one of them is an acceptable solution. This provides flexibility to the process engineer to choose one solution 
over the other depending on the requirement. It has been observed that powder-mixed dielectric significantly reduces surface heterogeneity contributing to increase process robustness. So, it contributes for the performance of the EDM process particularly when a high-quality surface is a requirement. However, the process is a complex one and deserves a thorough investigation on thermo-physical properties of the suspended particles. Few practical limitations like difficulty in operation of dielectric interchange, high amount of powder consumption, environmental requirements of fluid disposal and its higher initial cost (two to three times higher than the one required for a conventional EDM system) have restricted its frequent use. The optimization of powder characteristics (type, shape, size, concentration, etc.) also needs a thorough study.

\section{References}

Abbas N M, Solomon D G and Bahari M F 2007 A review on current research trends in EDM. Int. J. Machine Tools Manufact. 47(7-8): 1214-1228

Benedict G F 1987 Non-traditional manufacturing process. New York: Marcel Dekker

Chow H M, Yan B H, Huang F Y and Hung J C 2000 Study of added powder in kerosene for the micro-slit machining of titanium alloy using electro-discharge machining. J. Mater. Processing Technol. 101(1-3): 95-103

Deb K, Pratap A, Agarwal S and Meyarivan T 2002 A fast and elitist multiobjective genetic algorithm: NSGA-II. IEEE Trans Evol Comput 6(2): 182-197

Fenggou C and Dayong Y 2004 The study of high efficiency and intelligent optimization system in EDM sinking process. J. Mater. Processing Technol. 149(1-3): 83-87

Furutani K, Saneto A, Takezawa H, Mohri N and Miyake H 2001 Accertation of titanium carbide by electrical discharge machining with powder suspended in working fluid. Precision Eng. 25(2): 138-144

Gao Q, Zhang Q H, Su S P and Zhang J H 2008 Parameter optimization model in electrical discharge machining process. J. Zhejiang University Science A 9(1): 104-108

Jeswani M L 1981 Effects of the addition of graphite powder to kerosene used as the dielectric fluid in electrical discharge machining. Wear 70(2): 133-139

Joshi S N and Pande S S 2011 Intelligent process modeling and optimization of die-sinking electric discharge machining. Applied Soft Computing 11(2): 2743-2755

Kanagarajan D, Karthikeyan R, Palanikumar K and Davim J P 2008 Optimization of electrical discharge machining characteristics of WC/Co composites using non-dominated sorting genetic algorithm (NSGA-II). Int. J. Advanced Technol. 36(11-12): 1124-1132

Kansal H K, Singh S and Kumar P 2005 Parametric optimization of powder mixed EDM by response surface methodology. J. Mater. Processing Technol. 169(3): 427-436

Keskin Y, Kalkaci H S and Kizil M 2006 An experimental study for determination of effects of machining parameters on surface roughness in EDM. Int. J. Advanced Technol. 28(11-12): 1118-1121

Kuriakose S and Shunmugam M S 2005 Multi-objective optimization of wire electro discharge machining process by non-dominated sorting genetic algorithm. J. Mater. Processing Technol. 170(1-2): 133-141

Lin J L and Lin C L 2005 The use of grey-fuzzy logic for the optimization of the manufacturing process. J. Mater. Processing Technol. 160(1): 9-14

Lin Y C, Yan B H and Huang F Y 2001a Surface improvement using a combination of electrical discharge machining with ball burnish machining based on the Taguchi method. Int. J. Advanced Manufact. Technol. 18(9): 673-682

Lin Y C, Yan B H and Huang F Y 2001b Surface modification of Al-Zn-Mg aluminum alloy using the combined process of EDM with USM. J. Mater. Processing Technol. 115(3): 359-366

Mandal D, Pal S K and Saha P 2007 Modeling of EDM process using BP neural network and multiobjective optimization using non-dominating sorting GA. J. Mater. Processing Technol. 186(1-3): 154162 
Ming Q Y and He L Y 1995 Powder suspension dielectric fluid for EDM. J. Mater. Processing Technol. 52(1-3): 44-54

Mohri N, Saito N and Higashi M A 1991 A new process of finish machining on free surface by EDM methods. Annals of CIRP 40(1): 207-210

Montgomery D C 1997 Design and analysis of experiments. Fourth edition, New York: John Wiley Sons

Nixon K and Ravindra H V 2011 Parametric influence and optimization of wire EDM of hot die steel. Machining Science and Technol. 15(1): 47-75

Panda D K and Bhoi R J 2005 Artificial neural network prediction of material removal rate in EDM. Mater. Manuf. Process. 20(4): 645-672

Pecas P and Henriques E 2003 Influence of silicon powder-mixed dielectric on conventional electrical discharge machining. Int. J. Machine Tools Manufact. 43(14): 1465-1471

Pecas P and Henriques E 2008 Effect of the powder concentration and dielectric flow in the surface morphology in electrical discharge machining with powder mixed dielectric. Int. J. Advanced Manufact. Technol. 37(11-12): 1120-1132

Rao G K M., Janardhana G R, Rao D H and Rao M S 2008 Development of hybrid model and optimization of surface roughness in electric discharge machining using artificial neural networks and genetic algorithm. ARPN J. Eng. Appl. Sci. 3(1): 1512-1520

Schumacher B M 1990 About the role of debris in the gap during electrical discharge machining. Annals of CIRP 39(1): 197-199

Sen M and Shan H S 2007 Electro jet drilling using hybrid NNGA approach. Robot. Comput. Integrated Manuf. 23(1): 17-24

Singh S, Kansal H K and Kumar P 2005 Parametric optimization of powder mixed electrical discharge machining by response surface methodology. J. Mater. Processing Technol. 169(3): 427-436

Somashekhar K P, Ramachandran N and Jose M 2010 Optimization of material removal rate in micro-edm using artificial neural network and genetic algorithms. Mater. Manufact. Processes 25(6): 467-475

Su J C, Kao J Y and Tarng Y S 2004 Optimization of the electrical discharge machining process using a GA based neural networks. Int. J. Advanced Manufact. Technol. 24(2): 81-90

Tzeng F Y and Chen Fu 2003 A simple approach for robust design of high speed electrical-discharge machining technology. Int. J. Machine Tools Manufact. 43(3): 217-227

Tzeng Y and Chen F 2007 Multi-objective optimization of high speed electric discharge machining process using a Taguchi fuzzy-based approach. Mater. Des. 28(4): 1159-1168

Wang K, Gelgele H L, Wang Y, Yuan Q and Fang M 2003 A hybrid intelligent method for modeling the EDM process. Int. J. Machine Tools Manufact. 43(10): 995-999

Wong Y S, Lim L C and Lee L C 1995 Effect of flushing on electro-discharge machined surfaces. J. Mater. Processing Technol. 48(1-3): 299-305

Wong Y S, Lim L C, Rahuman I and Tee W M 1998 Near-mirror-finish phenomenon in EDM using powdermixed dielectric. Int. J. Advanced Manufact. Technol. 79(1-3): 30-40

Yu Z, Jun T and Masanori K 2004 Dry electrical discharge machining of cemented carbide. J. Mater. Processing Technol. 149(1-3): 353-357

Yang S H, Srinivas J, Mohana S, Lee D K and Balaji S 2009 Optimization of electric discharge machining using simulated annealing. J. Mater. Processing Technol. 209(9): 4471-4475

Yuan J, Wang K, Yu T and Fang M 2008 Reliable multi-objective optimization of high-speed WEDM process based on Gaussian process regression. Int. J. Machine Tools Manufact. 48(1): 47-60

Zhang L, Jia Z, Wang F and Liu W 2010 A hybrid model using supporting vector machine and multiobjective genetic algorithm for processing parameters optimization in micro-EDM. Int. J. Advanced Manufact. Technol. 51(5-8): 575-586

Zhao W S, Meng Q G and Wang Z L 2002 The application of research of powder mixed EDM in rough machining. J. Mater. Processing Technol. 129(1-3): 30-33 